\title{
Increasing Bee Forage for a Sustainable Bee Industry in
}

\section{Kenya}

\author{
Grace Asiko $^{1}$, Kiptarus Julius ${ }^{2}$, Mochorwa Jared ${ }^{1}$ and Koech Christine ${ }^{1}$ \\ 1. National Beekeeping Institute, Lenana, P.O. Box, 34188-00100, Nairobi, Kenya \\ 2. State Department of Livestock, Department of Animal Production, Hill Plaza,. P.O. Box, 34188-00100, Nairobi, Kenya
}

\begin{abstract}
Planting bee forage can profitably contribute to the sustainability of the beekeeping industry in Kenya. A variety of crops and vegetables are known to be suitable forage, since they are visited by most bee pollinators. In a pollination program at the National Beekeeping Institute, Lenana, various crops were selected to boost the bee forage range, after it was noticed that the prevailing honeybee colonies were dwindling drastically due to drought and other visible causes. The kales, sunflower and strawberry, were planted for the purpose. It was observed that the kales attracted most pollinators, ranging from insects to birds. The predominant insect species was Apis mellifera scutellata. Butterflies, stingless bees, birds, bats, wasps, hoppers, thrips and sugar ants were observed. Sunflower and strawberry, too, attracted butterflies besides bees, birds and other pollinators, but the latter had more flower visitors than the former. There was a 54\% increase in the number of domesticated honey bee colonies from five to eleven. The pollinator activity, which had ceased to revived as was physically observed from the "buzz of the bee, to the hoot of the woodpecker", signifying revamped activity. The honeybee turned out to be a more effective pollinator species adapted to the task.
\end{abstract}

Key words: Planting, bee forage, pollination, sustainability.

\section{Introduction}

In the wake of dwindling Bee forage resources, suitable quick flowering plants, with adequate nectar and pollen, such as: Kales, Sunflower and Strawberry, can be introduced to farmlands, to support and sustain Beekeeping industry [1-6]. Under field conditions, bees will normally have a choice of forage sources [7].

Logging, to pave way for infrastructure development, has impacted negatively on Beekeeping. The resultant micro-climate, evidenced by dry spells and change of bee routes, has led to dwindling honey bee colonies.

\subsection{The Study Objective}

(1) Increase bee forage by planting suitable, quick-flowering fruits and vegetables, to sustain Beekeeping for food security and sustenance of livelihoods.

Corresponding author: Grace Asiko, deputy director, research field: livestock production.
(2) Identify suitable pollinators to complement honeybees.

\subsection{Study Area}

National Beekeeping Institute, Lenana (Fig. 1), Coordinates: UTM 37M 0257490, 9858862, in Nairobi is situated about $6 \mathrm{Km}$ from Nairobi's Central Business District. It fringes Ngong forest (528 hectares), the only indigenous forest located within the confines of a capital city, Nairobi. The forest harbours rare animal and plant species, and is characterized by indigenous trees like Croton megalocarpus and tree plantations. It is interspersed with patches of grass. The area used to experience long rainfall seasons from March-May and short rainy seasons from October-December. The average rainfall was 1,000 $\mathrm{mm}$ whereas the mean temperature was $23{ }^{\circ} \mathrm{C}$. Common animals found within the Ngong forest include: Duiker, monkey, baboon and Bushbuck, among others. Forest resources include: honey, firewood, construction poles, medicinal herbs and shrubs. 


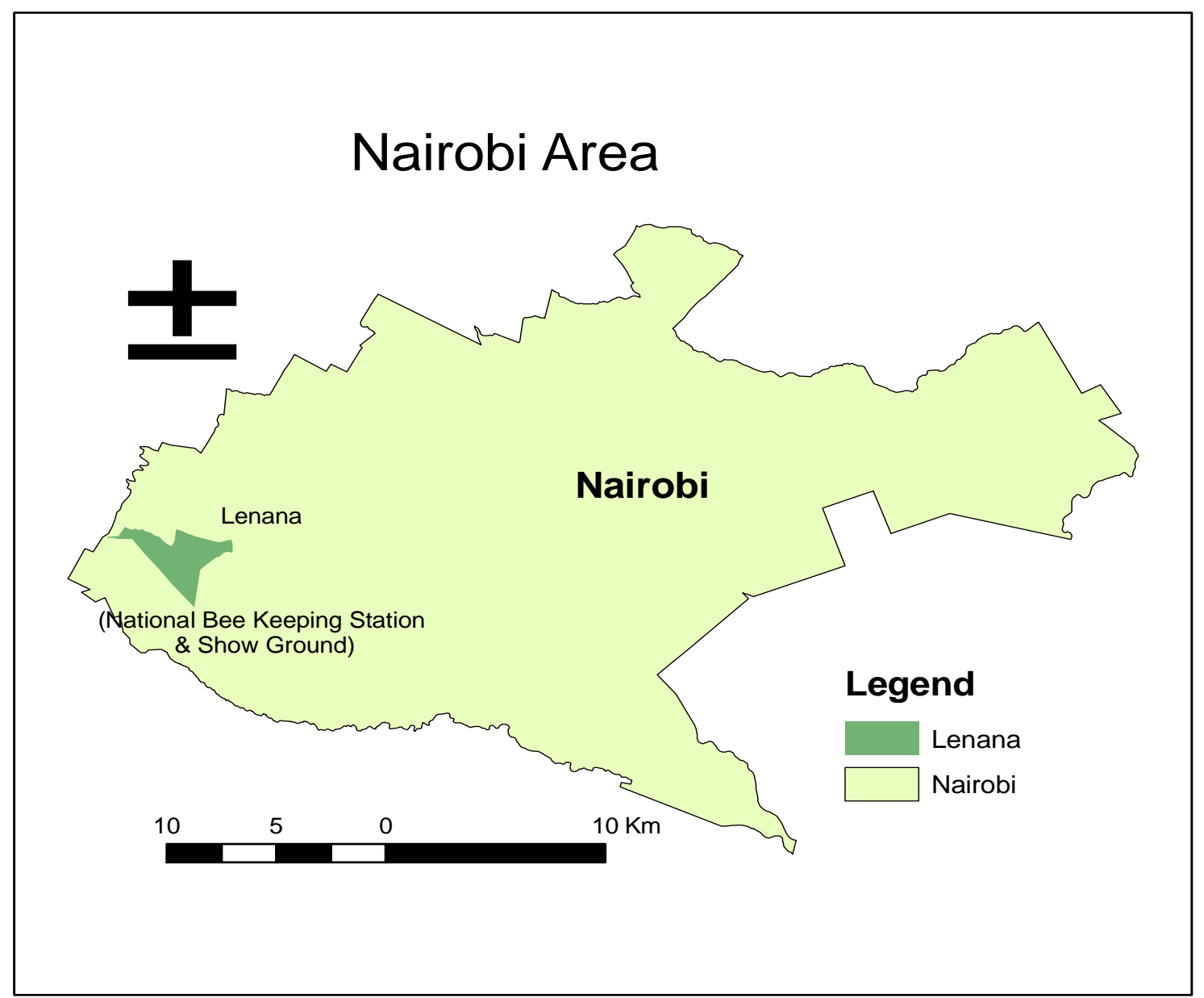

Fig. 1 Study area. National Beekeeping Station, Lenana.

Human activity, pauses threats to forest conservation efforts $[8,9]$.

\section{Materials and Methods}

\subsection{Materials}

$8 \times 24$ Meter portions of land, at the demarcated Coordinates was tilled and the three targeted crops: Kales, Sunflower and Strawberry (Fig. 2), planted on each parcel, under natural conditions.

\subsection{Methods}

Strawberry was propagated from older cultivars and 230 young splits planted for observation. Soil samples were taken for analysis, prior to planting (Fig. 4). Direct observation of flowers was made and flower visitors counted (Table 1), irrespective of task.

\section{Results and Discusion}

Planting Kales, Sunflower and Strawberry, increased bee abundance, due to improved resource availability, nectar and pollen. The plants, in turn improved in fruit/seed quality. Strawberry results indicated a significant increase in fruit quality, with a record $80 \%$ of fruits categorized under super class as a result of honeybee pollination together with other mixed Pollinators (bees, butterflies, birds and baboons (Table 1)). There was reduced mal-formed industry fruit quality in the greenhouse, where the honeybee was the sole Pollinator, accounting for $84 \%$ super quality fruits $(p<0.001, \mathrm{~F}=1.87$, d.f $=182$ on 968$)$.

The Kales attracted the highest number of pollinators in their diversity. Strawberry was second followed by Sunflower, with the least attractive number 

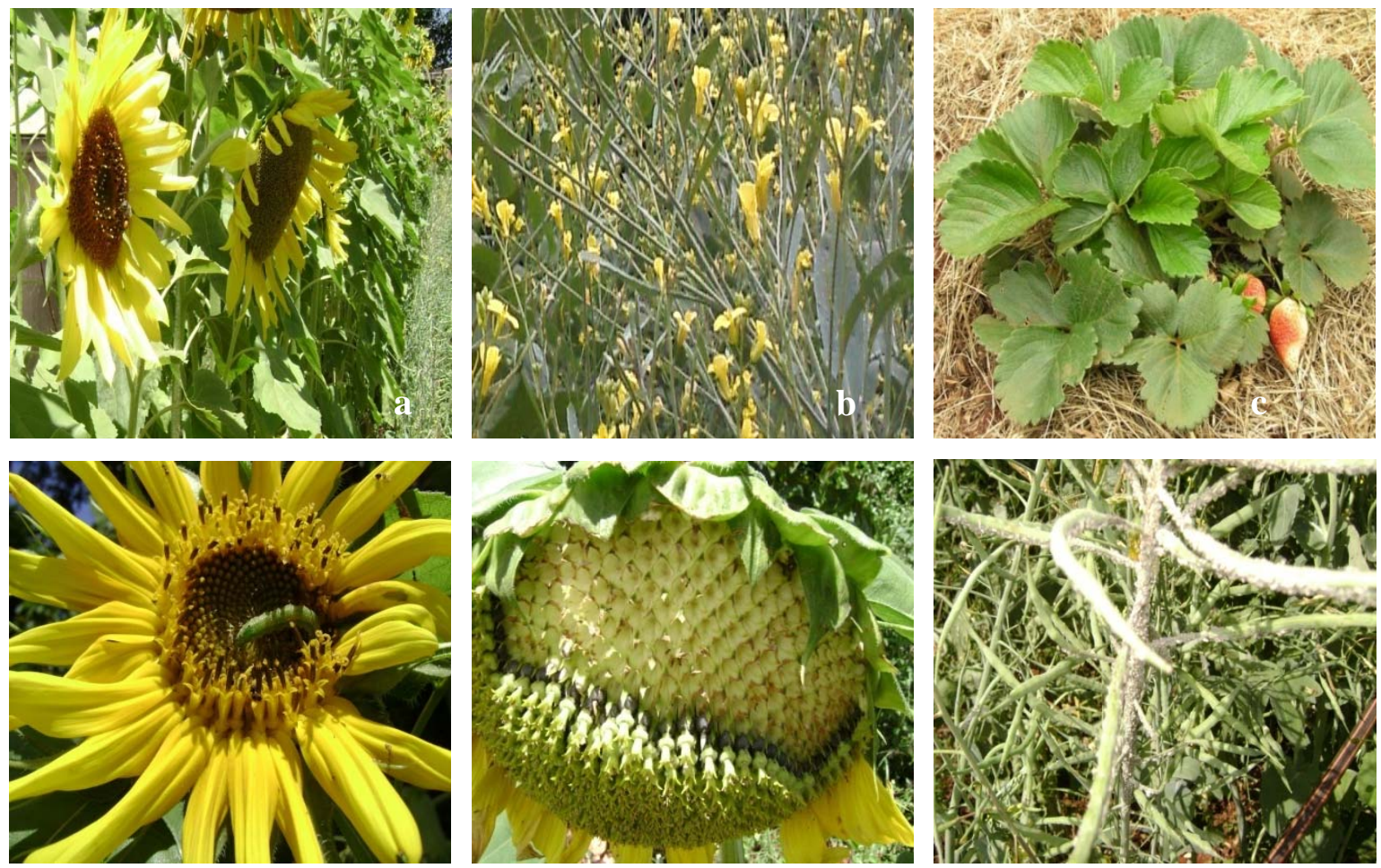

Fig. 2 Target bee forage crops, sunflower, kales, strawberry (a, b, c) and their pathogens.
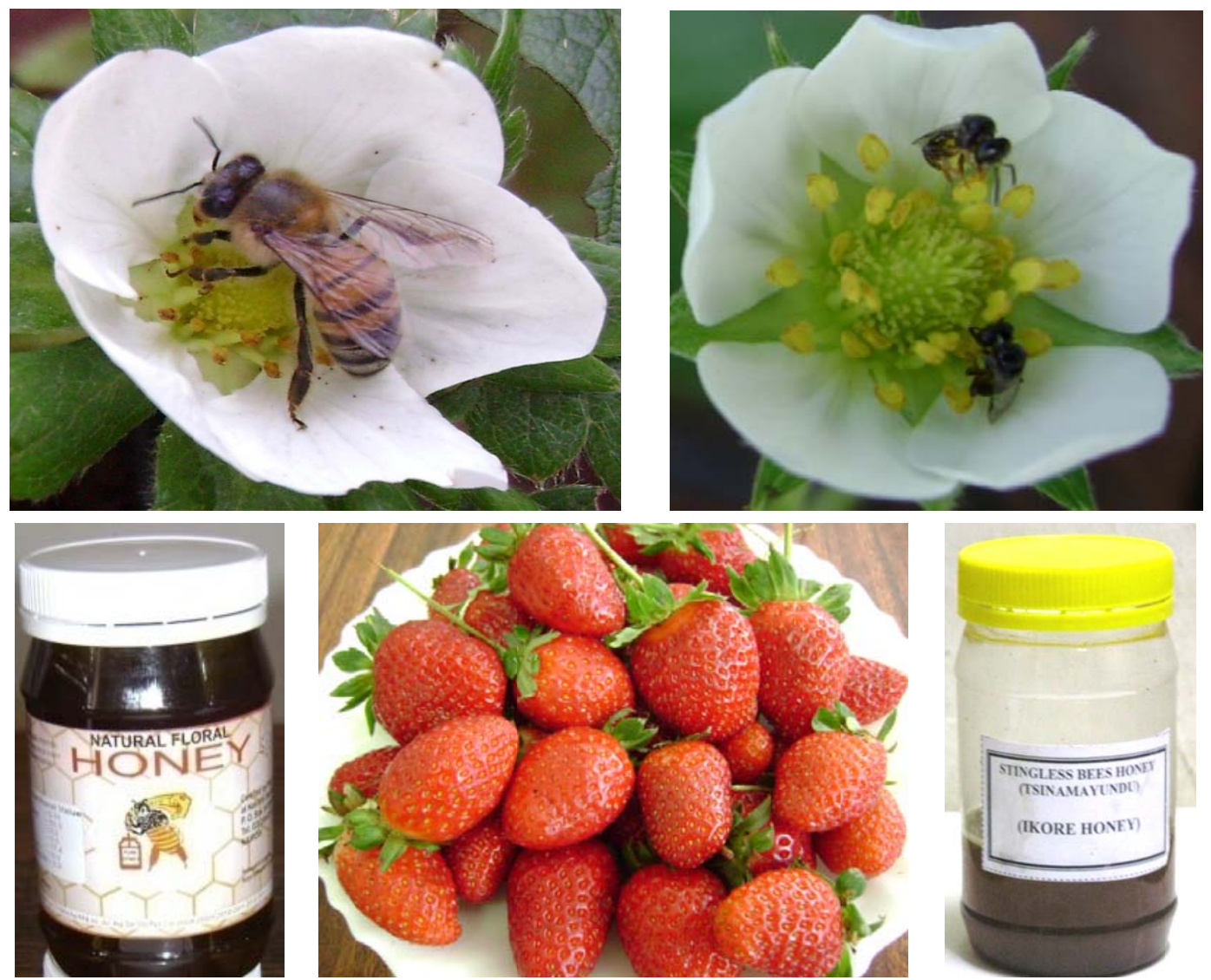

Fig. 3 Honeybees, HB and Stingless bees, ST, were the most frequent \& effective flower Pollinators. 
Table 1 Classification of pollinators as effective or occasional (Giannini et al. 2014) [11, 12].

\begin{tabular}{|c|c|c|c|c|}
\hline Pollinator & Brassica spp. & Helianthus annus & Fragaria x Ananassa sp. & Comment \\
\hline Apis melifera scutellata & $\sqrt{\mathrm{e}}$ & $\sqrt{\mathrm{e}}$ & $\sqrt{\mathrm{e}}$ & Nectar \& pollen \\
\hline Meliponula ferruginea & $\sqrt{ } \mathrm{e}$ & & $\sqrt{ } \mathrm{e}$ & Nectar \& pollen \\
\hline Hypotrigona gribodoi & $\sqrt{\mathrm{e}}$ & $\sqrt{ } \mathrm{e}$ & $\sqrt{\mathrm{e}}$ & Nectar \& pollen \\
\hline Hypotrigona ruspolii & $\sqrt{ } \mathrm{e}$ & $\sqrt{ } \mathrm{e}$ & $\sqrt{ } \mathrm{e}$ & Nectar \& pollen \\
\hline Other native bee species & $\sqrt{ } \mathrm{e}$ & & & Resource \\
\hline Birds (sun birds) & $\sqrt{0}$ & $\sqrt{0}$ & & Seed \\
\hline Birds (Ibis) & & & $\sqrt{ } 0$ & Devour fruit \\
\hline Bats & $V_{0}$ & & & Prey \& damage \\
\hline Wasps (Spechid) & $\sqrt{0}$ & $\sqrt{0}$ & $\sqrt{0}$ & Prey \\
\hline Wasps (Mammoth) & $\sqrt{ } \mathrm{o}$ & & & Prey \\
\hline Wasps (Pirate) & $\sqrt{o}$ & $\sqrt{ } \mathrm{o}$ & $\sqrt{o}$ & Prey \\
\hline Flies (House flies) & $\sqrt{ } 0$ & & $\sqrt{ } 0$ & Lay eggs \\
\hline Flies (Blue bottles) & $\sqrt{0}$ & & & Resource \\
\hline Ants (Componotus braunsi) & $\sqrt{ } \mathrm{o}$ & $\sqrt{ } \mathrm{o}$ & $V_{0}$ & Protection \\
\hline Sugar ants & $\sqrt{ } 0$ & $\sqrt{ } 0$ & $\sqrt{0}$ & Nectar \\
\hline Spiders & $\sqrt{0}$ & $\sqrt{0}$ & $\sqrt{0}$ & Nectar \& prey \\
\hline Thrips (Thysanoptera) & $\sqrt{ }$ o & & $\sqrt{ }$ & Resource \\
\hline Beetles (Longhorn, Cerambycidae) & $\sqrt{ }$ o & & & Pollen \& damage \\
\hline Beetles (Short horn) & $\sqrt{ } \mathrm{o}$ & $\sqrt{ } \mathrm{o}$ & $\sqrt{ } \mathrm{o}$ & Damage flower \\
\hline Butterfly (Brown, Acraea) & $\sqrt{\mathrm{e}}$ & & & Nectar \\
\hline Butterfly (Grey, Skipper)) & $\sqrt{ } \mathrm{e}$ & & & Nectar \\
\hline Butterfly (Belenois aurota; white, brown-veined) & $\sqrt{ } \mathrm{e}$ & & $\sqrt{ } \mathrm{o}$ & Nectar \\
\hline Butterfly (Greenish, Patch swallowtail) & $\sqrt{\mathrm{e}}$ & & & Nectar \\
\hline Hawk moths & $\sqrt{ } \mathrm{e}$ & & & Nectar \\
\hline *Baboon & & & $\sqrt{ }$ o & Devour fruit \\
\hline
\end{tabular}

Key: $\sqrt{ }=$ Flower visitor; $\sqrt{ } \mathrm{e}=$ Effective Pollinator; $\sqrt{ } \mathrm{o}=$ Occasional

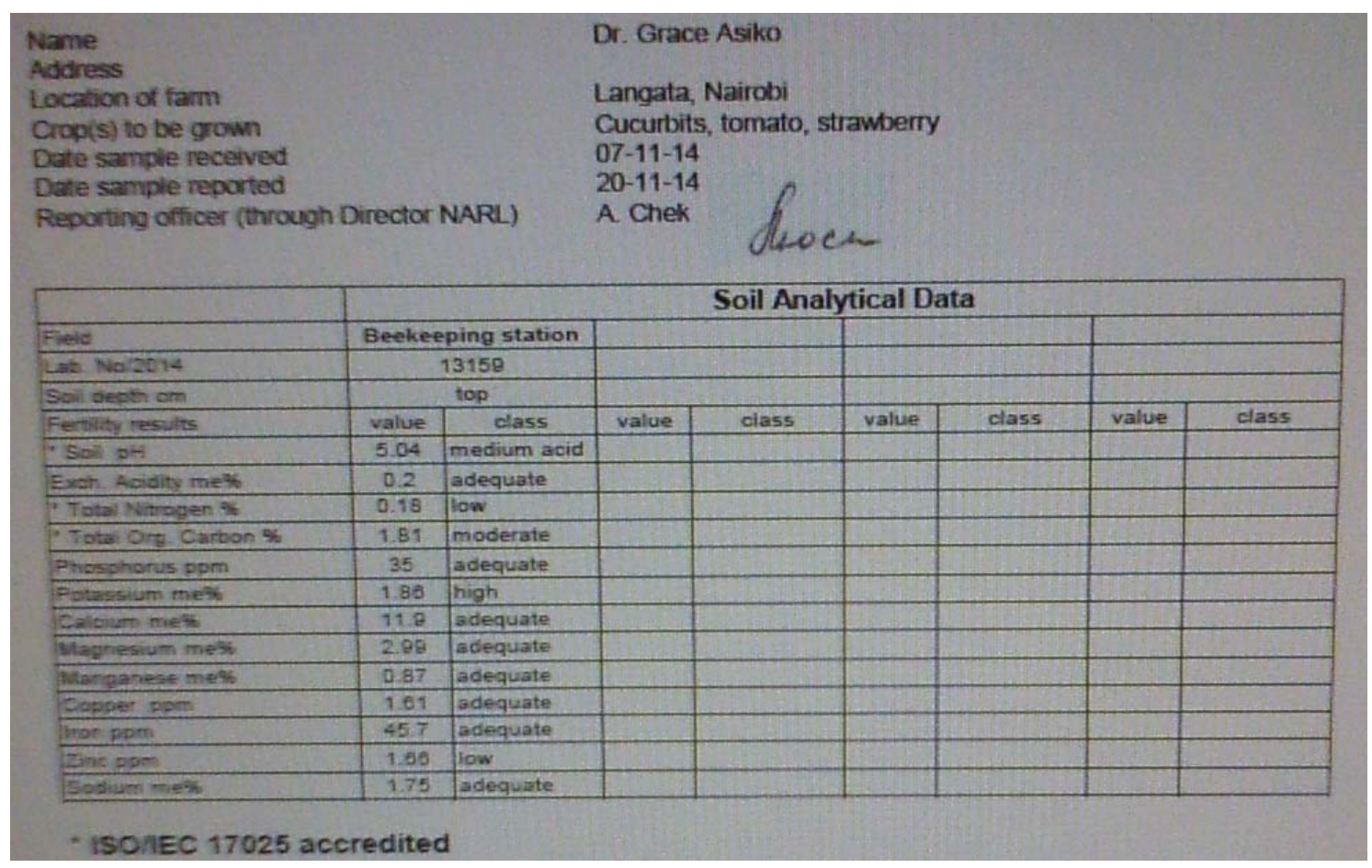

Fig. 4 Soil analysis report. KALRO, 2014. 
of effective flower visitors (Table 1). With increased stem-age, birds frequented Sunflower for seed (Fig. 2) and moderately visited Kales for the same, in what can best be described as "pollinator trend reversal." The honey bee continued to visit the 3 plants, Kales, Sunflower and Strawberry, even with increased stem-age, displaying her dominance and superiority over the other pollinators, due to her unique adaptation to undertake the task [10].

The honey bee carries huge volumes of nectar in her honey stomach and pollen in the pollen basket, corbicula, situated on its hind leg. Other late flower visitors include: wasps, spiders, flies and bats, some of which are predatory, providing a unique food-web. Ants provide protection whereas the smaller fauna, thrips and mosquitoes, are preyed upon [11].

\section{Conclusion}

Honeybees will migrate to localities with adequate forage in times of resource scarcity. The reverse is true in times of plenty. Beekeepers should be encouraged to plant bee forage for conservation of honeybee colonies (Fig. 2), increased food production and sustainability (Fig. 3).

\section{Acknowledgement}

We acknowledge The Principle Secretary, State Department of Livestock Production, Prof. Andrew Tuimur, for financial facilitation.

Staff, National Beekeeping Institute, particularly Nzano Patricia and Wekalao Kennedy, for additional records.

University of Nairobi, Animal Production Department Chairman, Prof. Joseph Junga and staff, for useful comments.

\section{References}

[1] Asiko, G. A. 2012. "Pollination of Strawberry in Kenya, by Stingless Bees (Hymenoptera: Meliponini) and Honey
Bee (Hymenoptera: Apini) for Improved Fruit Quality." Ph.D. thesis, University of Nairobi.

[2] Blaauw, B. R., and Isaacs, R. 2014. Flower Plantings Increase Wild Bee Abundance and the Pollination Services Provided to a Pollination-Dependent Crop. Journal of Applied Ecology.

[3] Kiatoko, N., Raina, S. K., Muli, E., and Mueke, J. 2014. Enhancement of Fruit Quality in Capsicum annum through Pollination by Hypotrigona gribodoi, in Kakamega, Western Kenya.

[4] Kinuthia, W. 2007. "Pollinators as an Indicator of ecosystem Health: A Landscape Approach to Biodiversity Conservation." In Wildlife Conference: Research Imperative for Biodiversity Conservation \& Management. Nairobi, Kenya.

[5] Martins, D. J., Gemmill, B., Eardley, C., Kinuthia, W., Kwapong, P., and Gordon, I. 2003. Plan of Action of the Africa Pollinators Initiative. Published by API Secretariat, 36.

[6] Sommeijer, M. J., De Rooy, G. A., Punt, W., and De Bruin, L. L. M. 1983. “A Comparative Study of Foraging Behaviour and Pollen Resources of Various Stingless Bees (Hymenoptera, Meliponinae) and Honeybees (Hymenoptera, Apinae) in Trinidad, West Indies." Apidologie 14: 405-24.

[7] Garbuzov, M., Couvillon, M. J., Schurch, R., and Ratnieks, F. L. W. 2015. "Honey Bee Dance Decoding and Pollen-Load Analysis Show Limited Foraging on Spring-Flowering Oilseed Rape, a Potential Source of Neonicotinoid Contamination." Agric, Ecosystems \& Environment.

[8] Kioko, E., Muthoka, P., Gikungu, M., and Malombe, I. 2006. Conservation of Useful Insects and Their Food Plants for Eco-Development in Dryland Districts of Eastern Kenya. Report, RRPSUD Research Report.

[9] Njoroge, G., and Gikungu, M. 2006. Status of Threatened Stingless Bees and Their Conservation Strategies for Poverty Alleviation and Sustainable Utilization in Semi-Arid Areas of Mwingi, Kenya. RPSUD Research Report.

[10] Roubik, D. W. 1989. Ecology and Natural History of Tropical Bees. Combrige University Press.

[11] Martins Dino, J. 2014. Our Friends, the Pollinators. A Handbook of Pollinator Diversity and Conservation in East Africa.

[12] Michener, C. D. 2000. The Bees of the World. John Hopkins University Press. 